\title{
O MARKETING DE SERVIÇOS \\ E SUAS IMPLICAÇÕES PARA UMA \\ ORGANIZAÇÃO SEM FINS LUCRATIVOS
}

Magali Costa Guimarães

Doutoranda em Psicologia Social e do Trabalho (UnB),

Mestre em Administração(magali@inesc.br)

\section{Resumo}

Este estudo restringiu-se em tentar compreender a visão de marketing de serviços dos responsáveis por uma organização sem fins lucrativos. O objetivo centrou-se em conhecer se tais pessoas conhecem quem são, o que desejam e esperam seus clientes, como vêm utilizando os conceitos de marketing e como avaliam a qualidade dos serviços executados na organização à luz da teoria de marketing. O estudo traz algumas reflexões importantes sobre a utilização do marketing de valor para as organizações sem fins lucrativos. Conclui-se através da pesquisa realizada que existe uma utilização de alguns elementos do marketing na organização estudada, mas de forma invertida e intuitiva.

Palavras-chave: Marketing, Organização sem Fins Lucrativos, Serviços

\section{ABSTRACT}

This study limited in trying to understand the vision of marketing of services of the responsible for a nonprofit organization. The objective was centered in knowing such people know who are, what want and wait your customers, as they are using the marketing concepts and as they evaluate the quality of the services executed in the organization to the light of the marketing theory. The study brings some important reflections about the use of the marketing of value for the nonprofit organizations. It is concluded through the research accomplished that an use exists of some elements of the marketing in the studied organization, but in an inverted and intuitive way.

Key words: Marketing, Non-profit Organizations, Services 


\section{INTRODUÇÃO}

A administração do Terceiro Setor tem se constituído em um tema de importância na última década. Segundo Nascimento (1999), incluem-se neste setor quaisquer iniciativas privadas na criação de entidades jurídicas não governamentais a perseguir o bem comum da coletividade, visando fortemente o interesse público, sem qualquer finalidade lucrativa.

Aqui, portanto, são incluídas as chamadas "organizações sem fins lucrativos" objeto de estudo neste trabalho. Tais organizações constituem em uma parte do conjunto de organizações que compõem o Terceiro Setor (SZAZI, 2001).

São inúmeras as organizações sem fins lucrativos existentes no país (igrejas, hospitais, museus, asilos, creches, orfanatos etc.). Grande parte delas sobrevive com escassez de recursos, falta de mão-de-obra qualificada ou de parceiros que possam abraçar sua causa.

Em sua maioria, tais organizações, prestam serviços essenciais ao ser humano contribuindo, seja para a melhoria da saúde física, seja para o amparo de pessoas necessitadas e famintas, seja para o apoio sócio-emocional a adolescentes ou a todo grupo familiar. São inúmeras as variedades de serviços prestados nestas organizações e, conforme enfatiza Drucker (1997), "seu 'produto' é um paciente curado, uma criança que aprende, um jovem que se transforma em um adulto com respeito próprio; isto é, toda uma vida transformada".

Importante agente social, boa parte destas organizações, ainda não acordou para instrumentos importantes das ciências administrativas e do marketing, que poderiam melhorar seu processo de gestão e auxiliar no alcance de suas metas. Recorrendo novamente a Drucker (1997), este ressalta que há quarenta anos atrás, "gerência" era considerada um palavrão nas organizações sem fins lucrativos americanas, pois gerência significava "negócios" e elas não eram empresas, já que não visavam lucros.

$\mathrm{Na}$ realidade brasileira, percebe-se que muitas dessas organizações também consideram termos como: "gerência", "estratégia" e "marketing" verdadeiros palavrões. É como se tais termos pudessem ir contra os seus valores humanitários ou religiosos. Contudo, o marketing estratégico e o marketing voltado para criar valor para o cliente, possuem instrumentos fundamentais que podem ser utilizados também por organizações sem fins lucrativos, de forma a garantir sua sobrevivência e o alcance de seus objetivos.

As mudanças no cenário atual começam a exigir destas organizações práticas gerenciais mais profissionalizadas, deixando de lado a informalidade que caracterizou seu processo de gestão em décadas passadas.

A partir desses pressupostos, o presente estudo teve por objetivo conhecer como são aplicados, mes- mo que de maneira informal, os conceitos de marketing de serviços em uma organização sem fins lucrativos. Buscou-se através deste, analisar a percepção dos membros responsáveis pela organização em relação a algumas questões fundamentais para uma postura mais gerencial como: o conhecimento de seus mercados-alvo (se sabem realmente quem são e o que desejam seus clientes), como avaliam a qualidade de seus serviços e como compreendem o conceito de marketing. Para isto foi realizada uma pesquisa de caráter exploratório, junto aos responsáveis por uma organização sem fins lucrativos localizada na cidade de Unaí-MG.

\section{FUNDAMENTAÇÃO TEÓRICA}

\subsection{Marketing de Serviços}

Conforme observado anteriormente, as organizações sem fins lucrativos são, principalmente, prestadoras de serviços. Torna-se importante, pois, conceituar "serviços" e suas implicações para o marketing.

O marketing de serviços assemelha-se ao marketing de produtos ou bens tangíveis, pois tanto um quanto o outro, são "produtos" destinados a oferecer valor aos clientes. Ambos buscam satisfazer determinadas necessidades e/ou desejos destes, contudo, a natureza diferente dos serviços exige uma atenção diferenciada por parte dos profissionais de marketing (CHURCHILL; PETER, 2000).

Kotler (1998) define serviços como: "qualquer ato ou desempenho que uma parte possa oferecer a outra e que seja essencialmente intangível e não resulte na propriedade de nada". Segundo Semenik e Bamossy (1995) um bem tangível pode até ser usado na prestação de um determinado serviço, como por exemplo, o aluguel de um carro ou uma viagem de avião. Mas isto não significa que o comprador tenha adquirido a propriedade dos mesmos.

Estas considerações revelam, assim, uma das características essenciais dos serviços - a intangibilidade. Sobre tal característica, Fitzsimmons e Fitzsimmons (2000) ressaltam que diferentemente dos produtos, que são objetos, os serviços são idéias e conceitos, sua natureza intangível não permite que o consumidor possa vê-lo, tocá-lo e testá-lo antes da compra.

Assim, ao comprar um pacote de viagem não há como experimentá-lo antecipadamente, ver e sentir como será a comida, a hospedagem etc. Kotler (1998) afirma que, devido a esta incerteza, o comprador irá buscar sinais que evidenciam qualidade naquele "produto" que irá adquirir. Seja buscando recomendações de terceiros para saber sobre a idoneidade da empresa de turismo, seja analisando fotos do hotel etc. É nesse sentido que ele alerta para a necessidade das empresas de serviços acrescentar evidências físicas e imaginárias 
a suas ofertas abstratas de forma a reduzir a incerteza sentida pelo cliente.

Fitzsimmons e Fitzsimmons (2000) salientam que a participação do cliente no processo dos serviços é outra característica exclusiva destes. Determinados serviços demandam mais a presença e participação do cliente que outros. Pode-se afirmar que em uma psicoterapia a participação ativa do cliente é essencial, sem o qual torna-se impossível a prestação do serviço, assim como, em um processo educacional, onde a qualidade do serviço prestado será também determinado pelo esforço do cliente (aluno).

Com os exemplos anteriores, torna-se possivel perceber outra característica dos serviços: a inseparabilidade. A produção e o consumo dos serviços ocorre simultaneamente. Churchill e Peter (2000) salientam que esta proximidade dos profissionais com os seus clientes demanda, dos mesmos, capacidade de manter um bom relacionamento e a prestação de um serviço de qualidade. É necessário ser capaz de, não só atrair, mas de manter o cliente. Essa afirmação é extremamente importante, pois o contato direto entre empregado e cliente exige daquele, qualificação, empenho e comprometimento com os objetivos da empresa para a qual trabalha.

Outra característica importante dos serviços é a perecibilidade. Os serviços são perecíveis, não podem ser estocados e, se não forem usados, estarão perdidos. Kotler (1998) afirma que esta característica não representa um problema quando a demanda é estável, mas torna-se mais difícil de ser administrada quando a demanda é cíclica. Estratégias especiais de marketing devem ser implementadas para lidar com essas flutuações de oferta e procura.

A variabilidade - outra característica dos serviços implica numa dificuldade de uniformização, na medida em que os serviços são altamente variáveis e dependem de quem os executa e de onde são prestados (Kotler, 1998).

Tais aspectos chamam a atenção novamente para a importância do marketing interno, visando o treinamento e a qualificação daqueles que lidam diretamente com o cliente (funcionários), bem como, a satisfação e motivação destes em relação ao ambiente de trabalho (KOTLER, 1999; CHURCHILL; PETER, 2000).

Outra providência a ser tomada para lidar com esta variabilidade, afirma Kotler (1998), é padronizar o processo de prestação de serviços, utilizando ferramentas como o fluxograma para conhecer pontos fortes e fracos do serviço envolvido. Monitorar a satisfação do consumidor através de sistemas de sugestões, reclamação etc., é também relevante para conhecer como os serviços estão sendo percebidos pelo consumidor. Kotler (1998) também chama a atenção para a dificuldade que o próprio cliente tem de avaliar a qualidade de um serviço, mesmo após tê-lo recebido. Para ele as empre- sas de serviços enfrentam três grandes desafios: aumentar sua diferenciação competitiva, sua qualidade e produtividade. São estratégias necessárias para criar mais valor ao cliente, criando lealdade do mesmo em relação à empresa.

McKenna (1999) alerta para o fato de que as fronteiras entre produtos e serviços estão desaparecendo rapidamente na atualidade. Ocorre, segundo ele, uma "servilização" dos produtos e a "produtilização" dos serviços. Tal fato é de suma importância para a aplicação de estratégias de marketing, tanto para empresas de produtos quanto para as de serviços.

Serão vistas, a seguir, considerações dos diversos estudiosos do marketing sobre a utilização do marketing de serviços nas organizações sem fins lucrativos. É possível a este tipo de organização utilizar os conceitos do marketing de serviços? É necessário a estas organizações - também - criar mais valor aos clientes?

\subsection{Marketing de Serviços para Organizações Sem Fins Lucrativos}

Toda organização está inserida em um ambiente e estabelece relações de troca para a obtenção de recursos e para transformá-los em produtos ou serviços e distribuí-los de forma a atender seus mercados-alvo. O objetivo é sempre a satisfação das necessidades dos clientes (SOUZA, 1993). Portanto, a aplicação dos conceitos de marketing por empresas que não visam lucro, apesar de algumas especificidades, segue basicamente os mesmos princípios do marketing aplicado às empresas.

Churchill e Peter (2000) consideram de extrema importância que tais organizações também conheçam seus clientes e busquem criar mais valor para eles.

Semenik e Bamossy (1995) definem como organização sem fins lucrativos "qualquer instituição pública ou privada envolvida no provimento de uma oferta de mercado sem a finalidade de obter lucro. A rigor, essas organizações caem na categoria de organizações de serviço". Eles afirmam que a aplicabilidade dos conceitos de marketing a esse tipo de organização foi proposta há muitos anos [1969] em um artigo de Kotler e Levy. Salientam que em tal artigo preconizavam o marketing como uma atividade social que abrangia não só as empresas comerciais. Para eles, as organizações sem fins lucrativos utilizavam, através de seus gerentes, tarefas de marketing mesmo sem estar cientes disto.

Kotler (apud SOUZA, 1993) considera importante no marketing para organizações sem fins lucrativos, a preocupação com as relações entre a organização e seus diferentes públicos e mercados; em conhecer e compreender o que a organização troca com os diferentes públicos (o que cada parte dá e recebe). Nesse sentido, a organização sem fins lucrativos, como qualquer outra organização, deve estar atenta aos stakebolders: comuni- 
dade local, grupos de pressão, "concorrentes" (outras instituições de filantropia), funcionários, diretoria, órgãos governamentais, fornecedores.

Kotler, em entrevista a Peter Drucker, considera que essas organizações, muitas vezes, têm claro para si as necessidades que gostariam de atender, mas normalmente não as compreendem do ponto de vista dos clientes. Ele diz que na maioria das vezes as organizações sem fins lucrativos partem para a propaganda antes de terem uma identidade definida, um foco real no cliente, praticando o marketing na ordem inversa. Assim como nas empresas, o marketing nessas instituições deve, segundo ele, em primeiro lugar pesquisar os clientes para compreender o mercado e suas necessidades. Em segundo lugar, deve desenvolver a segmentação e conscientizar-se a respeito dos diferentes grupos com os quais se interage. Terceiro, desenvolver políticas, práticas e programas visando a satisfação destes grupos. O último passo é a comunicação destes programas (DRUCKER, 1990).

Portanto, pode-se afirmar que para Kotler, uma visão estratégica deve estar presente também nos responsáveis por organizações sem fins lucrativos, onde conhecer o ambiente e as forças que atuam sobre ele torna-se fundamental.

Churchill e Peter (2000) assinalam que enquanto o objetivo principal do marketing de uma empresa é o lucro, o marketing das organizações sem fins lucrativos pode ter outros propósitos, como por exemplo, o incentivo ao trabalho de voluntários na instituição.

Estes autores, corroborando com as idéias de Kotler, salientam que algumas características destas organizações tornam seu marketing desafiador. Uma destas características é que os financiadores da organização nem sempre são os usuários de seus serviços. Estabelecendo com isto a existência de pelo menos dois grupos que deverão ser atendidos em suas necessidades e desejos (CHURCHILL; PETER, 2000).

Semenik e Bamosy (1995) fazem uma análise importante sobre o estabelecimento do marketing mix das organizações sem fins lucrativos. Para eles os desafios enfrentados são maiores nestas que nas empresas de serviços orientadas para o lucro. Com relação ao serviço, eles ressaltam a dificuldade de ajustar seu "produto" para atender à demanda do cliente. Na medida em que a organização deve preocupar-se com outros agentes importantes com os quais se relaciona.

Em instituições religiosas evidencia-se tal dificuldade, pois, nem sempre lhes é possível ater-se somente aos desejos e necessidades dos clientes, mas sim a preceitos filosóficos e religiosos, ou a interesses do grupo ao qual está ligada. Nesse sentido, Semenik e Bamosy (1995), orientam para a possibilidade de vender tal serviço para grupos que se identifiquem com os valores e intenções da organização. Com relação ao preço, observam a importância destas organizações identificarem e reduzirem todas as formas de custo percebidas pelos clientes potenciais. É necessário, por exemplo, que as pessoas percebam que suas doações estão sendo bem aplicadas pela organização.

Para os autores, das variáveis do marketing mix, a comunicação é o mais acessível e eficiente instrumento estratégico disponível às organizações sem fins lucrativos. Acrescentam que os meios de comunicação estão sempre desejosos e abertos a veiculação de mensagens que sejam de utilidade pública: "os jornais estão sempre em busca de artigos de verdadeiro interesse público; e voluntários da comunidade atuam na venda pessoal. Essas atividades, combinadas com a propaganda paga convencional, permitem que as organizações sem fins lucrativos possam se comunicar com o mercado" (SEMENIK; BAMOSY, 1995).

Ainda em relação à comunicação, Rodrigues (2001a), observa que conteúdo da comunicação das organizações sem fins lucrativos com seus públicos recai fortemente sobre campanhas de captação de recursos. Para essa autora, este trabalho de captação fica facilitado se houver clareza nos propósitos, acompanhada por prestação de contas com formato e periodicidade fixa. Enfatiza ainda que tais práticas necessitam de um plano de comunicação que contemple tanto o motivo da captação, a forma e a prestação de contas, parte fundamental, sem a qual a repetição do processo e a credibilidade da entidade ficam comprometidas.

Em seu estudo, Rodrigues (2001b) revela que a criação de marca pode ser uma importante ferramenta para as organizações sem fins lucrativos, pois intensifica relacionamentos e contribuem para criar uma identidade, traduzida em símbolos e experiências de intervenção social competente.

Verifica-se, portanto, que os mesmos elementos do marketing para as empresas que visam lucro podem ser ajustados às organizações sem fins lucrativos. Tais elementos devem ser aplicados tendo como referência a finalidade da organização, sua missão, seu objetivo, seu "produto" e seus clientes. É necessário que os tomadores de decisão tenham claros para si estes aspectos, para que possam estabelecer estratégias adequadas, para atingir o público e ao objetivo adequado à organização.

\section{METODOLOGIA}

Os dados para este estudo foram recolhidos a partir de entrevista pessoal à 6 membros da diretoria e à coordenadora do Abrigo Frei Anselmo da Sociedade São Vicente de Paulo de Unaí - MG. A escolha dos entrevistados foi dirigida, buscando-se a totalidade dos membros da diretoria (presidente, secretário, tesoureiro e diretor).

Buscou-se através de entrevista semi-estruturada conhecer a visão dos responsáveis pela instituição su- 
pra citada, a respeito do marketing de serviços, como utilizam (mesmo que de maneira informal) seus conceitos; se conhecem quem são e o que desejam seus clientes, bem como, os serviços que oferecem e a qualidade dos mesmos.

É uma pesquisa de caráter exploratório, com uma abordagem essencialmente qualitativa, que não tem como finalidade a generalização e aprofundamento de outras questões pertinentes à organização. $O$ objetivo final foi analisar o discurso dos entrevistados à luz do referencial teórico de marketing de serviços. Nesse sentido, buscou-se identificar os reflexos que a visão dos responsáveis (baseada no senso-comum) têm sobre a organização, bem como, mudanças que poderiam ser implementadas.

\subsection{Abrigo Frei Anselmo da S.S.V.P. como prestador de serviços}

O Abrigo Frei Anselmo da S.S.V.P. de Unaí é uma instituição de caráter filantrópico fundado em 1989 por leigos católicos, integrantes da Sociedade São Vicente de Paulo. É mantido por subvenções municipais, aposentadorias de parte dos internos, contribuiçôes das Conferências Vicentinas e doadores diversos da comunidade local.

Abriga atualmente, 140 pessoas em regime de internato, recebendo alimentação, cuidados médicos, vestuário, etc. Possui uma ampla estrutura física (160 leitos, salas de TV, refeitórios, lavanderia, farmácia, enfermaria, clínica fisioterápica, gabinete odontológico etc).

Participam do quadro de diretores 13 pessoas, sendo 11 participantes da S.S.V.P (Vicentinos). O presidente e o vice-presidente do Abrigo são escolhidos pelo presidente do Conselho Central de Unaí da S.S.V.P. (este é eleito pelos representantes de cada conselho das Conferências Vicentinas), sendo que o restante da diretoria é escolhido pelo presidente do Abrigo, podendo estes ser Vicentinos ou não. A organização conta com 31 funcionários, sendo a coordenadora responsável pela administração e organização do trabalho diário, mas a tomada de decisão, as resoluções principais, partem da diretoria.

O Abrigo Frei Anselmo é conhecido por grande parte da população como "Lar dos Velhinhos", nome antigo dado ao asilo. Hoje, socorre não apenas idosos, mas entre os internos existem deficientes físicos, deficientes mentais, doentes mentais e também idosos. São pessoas que em sua maioria não tem família, ou a família encontra-se impossibilitada de cuidar principalmente, por carência sócio-econômica.

Apesar de sua estrutura ampla e de ser o maior Abrigo da região Noroeste de Minas Gerais, a organização enfrenta problemas, assim como tantas outras organizações sem fins lucrativos. Dentre estes, é importante destacar as dificuldades financeiras que impedem que muitas melhorias sejam implantadas.

\section{ANÁLISE DOS RESULTADOS}

Descrevendo o perfil dos entrevistados, é possível concluir que se tratam de pessoas religiosas e que têm como valor, a caridade e o auxílio aos necessitados. São pessoas que variam em grau de escolaridade, profissão e nível social. Esta heterogeneidade resulta numa diversidade de idéias que refletem no modo de explicar e de perceber a realidade organizacional.

Questionados sobre quem consideram clientes do Abrigo Frei Anselmo, cinco responderam que seriam os internos da organização, enquanto dois disseram ser a sociedade ou o "visitante" o maior beneficiário e, portanto, o cliente. Dois dos membros disseram que a sociedade é "parceira", outro não usou esta terminologia, mas a vê como uma contribuinte para a manutenção da organização, mas não como cliente.

Sobre o tipo de serviços que o Abrigo oferece ao seu cliente, foram citados fundamentalmente: conforto, alimentação, vestuário, apoio emocional, moradia, assistência médica, educação espiritual. Os beneficiários de tais serviços são os internos, sendo que apenas um dos membros ressaltou que o Abrigo "vende conforto $e$ paz para aqueles que visitam. Às vezes estamos tristes e quando chegamos na instituição vemos aqueles que sofrem e passamos a refletir sobre nossa vida" - para este o cliente é a sociedade.

No que se refere à qualidade do serviço prestado pela organização, a maioria concorda que é necessário melhorar. Solicitados a atribuir uma nota de 0 a 10 a este aspecto, as notas dadas foram: uma nota 6 , três notas 7, duas notas 8 e apenas um avaliou como 10 a qualidade do serviço prestado, mas ressalta logo a seguir que é "suspeito" pois é "fã" da instituição e admira o trabalho feito: "acho que pode ter falbas, onde tem gente, tem defeito, mas acho que fazemos o melbor pelo interno".

Percebe-se que não existe um critério formal de avaliação que possa medir a qualidade do serviço realizado e os resultados da organização, não havendo unanimidade quanto à qualidade do serviço prestado. Quatro membros disseram que seria importante haver tal avaliação, enquanto os outros restantes salientaram que a avaliação é feita nas observações do dia-a-dia, através das reclamações (ou elogios) recebidos dos visitantes e dos Vicentinos; ou mesmo através de informações passadas pela coordenadora do Abrigo à diretoria.

Com relação ao que o cliente espera da organização, aqueles que consideraram o interno como cliente, ressaltaram, principalmente, aspectos afetivos como carinho, diálogo, mais visitas, paz, além de segurança, melhor qualidade de vida, cuidados médicos e alimentação. Os que consideraram a sociedade como cliente disseram que estes esperam que a organização continue realizando um bom trabalho e demonstrando carinho aos internos do abrigo. Entretanto, há dúvidas se 
existe a correspondência entre o que os clientes esperam e o que recebem na realidade: um dos membros disse que haveria "um pouco", outro "mais ou menos" e outros dois disseram que "quase total", sendo que os três restantes afirmaram que existe correspondência entre o que os clientes esperam e o que é feito.

No que diz respeito às dificuldades enfrentadas pela organização, o aspecto financeiro é o mais ressaltado, depois vem assistência médica e o reduzido número de visitas aos internos. Apenas um dos membros ressaltou a dificuldade em relação à atitude das pessoas ligadas à organização ("às vezes falta 'vontade' para fazer") e também a necessidade de escutar os clientes (os próprios internos) e conhecer o que eles desejam: "ouvir dos próprios internos quais são as suas necessidades". Outro membro, que tem a percepção dos visitantes como clientes, coloca como dificuldade a falta de atendimento adequado destes, quando em visita ao Abrigo. Para ele falta orientar e informar sobre a organização. Considera assim, que os funcionários possuem dificuldade ou mesmo falta de qualificação para fazer este papel. Como os membros assumiram recentemente a diretoria, alguns ainda demonstram certa dificuldade de propor soluções, mas são coesos, quanto a necessidade de implementação de melhorias.

Quanto à solução dos problemas financeiros, um dos membros ressaltou que estão providenciando documentaçôes para o processo de aposentadoria e realizando promoções. Outro considera que a divulgação do trabalho do Abrigo nos meios de comunicação é fundamental, bem como, buscar parcerias com escolas e entidades, enfatizando a necessidade de fazer com que as pessoas conheçam a organização e suas necessidades para levá-las a contribuir. Sobre outros aspectos, relatam alguns projetos para melhoria da estrutura física (como a cozinha), projeto de uma horta para melhoria da alimentação, melhoria da segurança (construção de uma portaria), também estão buscando criar uma conscientização maior dos próprios Vicentinos para dar apoio espiritual e realizar maior número de visitas aos internos do Abrigo. Apenas um dos entrevistados ressaltou a necessidade de qualificação e ampliação do número de funcionários para melhoria dos serviços na organização.

Os membros da diretoria são coesos quanto à participação dos funcionários na avaliação e solução dos problemas enfrentados pela organização: "são os principais parceiros na resolução de problemas", argumenta um deles, "são os que convivem o dia todo e sabem dos problemas do Abrigo", reforça outro. É também de consenso que todos os membros da diretoria participam das tomadas de decisão e na resolução dos problemas: "Todos são ouvidos, tudo é votado", afirmou um deles.

Dentre os entrevistados, dois desconheciam a palavra marketing, enquanto os cinco restantes vêem o marketing como propaganda, divulgação, relacionando este termo com mídia e televisão.

\subsection{O Marketing de Serviços e o Abrigo Frei Anselmo da S.S.V.P}

Através dos relatos e das análises anteriores, percebe-se que existe a preocupação de toda diretoria em melhorar a qualidade de vida daqueles que usufruem os serviços do Abrigo, ou seja, o interno.

Existe uma coesão do grupo no que se refere a uma melhoria, principalmente em termos de assistência afetiva e espiritual ao interno, na medida em que a gestão anterior, já realizou muitas melhorias estruturais. Buscando analisar os discursos dos responsáveis pela organização e suas práticas à luz da teoria de marketing, pode-se perceber, entretanto, algumas idéias ou concepções que prejudicam, ou limitam, o desenvolvimento da organização. São idéias e concepções baseadas no senso comum e no sentimento intuitivo dos diretores.

A falta de uma visão unânime sobre quem são os clientes da organização por si só já dificulta a elaboração de estratégias adequadas para o atendimento eficaz dos mesmos. Esta indefinição impede a focalização de estratégias que sejam capazes de atender e satisfazer, eficazmente, as necessidades dos clientes.

Além disso, conforme ressaltado anteriormente, a partir das idéias de Kotler (1998), e também Churchill e Peter (2000), é necessário que a organização conheça seus vários públicos, para atendê-los em suas necessidades. A organização sem fins lucrativos deve, portanto, conhecer e dar atenção, também, aos diversos stakeholders com os quais lida. Nesse caso específico, existem grupos que exercem forte pressão (como os Vicentinos e comunidade local) e que também necessitam ser escutados.

Drucker (1997, p. 73) também enfatiza essa necessidade. Para ele tanto os doadores [sociedade/comunidade local] devem ser considerados como clientes pelas organizações sem fins lucrativos, como aqueles que usufruem mais diretamente de seus serviços - no caso do Abrigo - os internos. Afirma, em relação a este último, ser necessário que não sejam vistos apenas como "[...] alvos de generosidade, as quais a instituição faz bem. Eles são clientes que precisam ser satisfeitos".

Esta forma de pensar o interno é de suma importância, pois faz com que as pessoas que lhes prestam o serviço, sejam mais profissionais, saindo da posição de quem está fazendo um favor apenas.

Assim, é fundamental que haja uma definição clara para todos os tomadores de decisão e para o restante dos membros da organização de: "quem são" os clientes do Abrigo? O que eles desejam e esperam da organização? É necessário questionar e conhecer o que tem valor para eles. Ambos (interno e sociedade) necessitam ser 
escutados em suas necessidades e desejos para que se possa criar mais valor e superar suas expectativas.

É importante que a organização questione: o que o interno espera e deseja da organização? Quais são suas necessidades e desejos? Com relação à sociedade, é necessário que a organização perceba e conheça não só os clientes (já doadores), como também o cliente em potencial (possível doador). Assim, é necessário conhecer o que cria mais valor para os Vicentinos [doadores já fixos e que possuem uma ligação maior com o Abrigo] e para os outros públicos da comunidade local. Tais aspectos valem tanto para obtenção de doações, como para atração de voluntários e de maior número de visitantes à instituição.

Drucker (1997) salienta que mais importante que buscar fundos, é "desenvolver fụndos". Isto significa criar um relacionamento de longo prazo com o cliente, criando lealdade, buscando criar um público que apóie e se identifique com os valores da organização. Para isto, ressalta que "não só apelos emocionais" devem ser utilizados, mas também "apelar para a razão" através, principalmente, da demonstração de seus resultados. É preciso assim, que a organização defina claramente quais os resultados deseja alcançar e demonstrem isto para os doadores. Eles necessitam ver e perceber de forma clara, como seu dinheiro está sendo usado e aplicado pela instituição (diminuindo a intangibilidade do serviço).

Aqui valem as considerações de Rodrigues (2001b) em relação à necessidade da organização prestar contas ao seu público, favorecendo sua credibilidade e criando uma imagem positiva capaz de estimular novos doadores. Constitui-se, portanto, em uma forma de reduzir as incertezas do cliente (doadores).

Após este conhecimento, tornar-se-ia mais fácil definir os serviços essenciais que o Abrigo deve oferecer, quem deve executá-los, bem como, a qualidade com que tais serviços devam ser realizados. Um fator importante se refere à visão de todo grupo entrevistado em relação à participação do funcionário na resolução de problemas, esta visão como "parceiro" é peça fundamental para a realização de mudanças. Entretanto, no que se refere ao funcionário, pôde-se perceber outro aspecto negligenciado pela quase totalidade dos membros da diretoria entrevistados: a qualificação dos funcionários (apenas dois demonstraram alguma preocupação com este fato). Conforme salientam os diversos autores citados no início deste artigo, o treinamento e qualificação dos funcionários são de suma importância para a lidar com características próprias dos serviços (variabilidade, inseparabilidade, intangibilidade).

Seguindo o que sugerem os estudiosos do marketing de serviços, a organização deve primar pela qualidade dos serviços através da qualificação de seu corpo de funcionários. São estes quem mantêm um relacionamento direto com os clientes (internos e socie- dade/doadores). É necessário, pois, buscar a "produtilização" dos seus serviços perante, principalmente à sociedade, "demonstrando" a qualidade dos serviços prestados. É uma forma importante de lidar com as características do marketing de serviços, reduzindo as incertezas e atendendo aos desejos dos clientes. O marketing interno torna-se importante, na medida em que somente funcionários satisfeitos, motivados e comprometidos com os objetivos da organização são capazes de realizar serviços de qualidade superior.

É também de fundamental importância, que todos da organização estejam voltados para a criação de valor ao cliente (funcionários, coordenadores, diretoria, voluntários). Nesse sentido, o estabelecimento da missão da empresa e a definição de metas são essenciais para que todos conheçam aquilo que a organização deseja alcançar, e o que é esperado de cada um de seus membros. A indecisão sobre a correspondência entre o que os clientes esperam e o que é feito pela organização, também implica em um desconhecimento e descuido em relação ao cliente.

Conforme afirma Kotler (1998), as organizações sem fins lucrativos podem utilizar os mesmos instrumentos e ferramentas do marketing de serviços das empresas que visam lucro, portanto, pesquisas, e instrumentos formais de monitoração da satisfação do cliente, reclamações e sugestões poderiam ser úteis para a avaliação da qualidade dos serviços e para conhecer melhor o cliente, percebendo o que tem, realmente, valor para eles. Nesse caso específico, percebe-se que a falta de instrumentos formais faz com que cada um, intuitivamente, considere o que é mais importante, ou essencial para a organização, sem saber se é importante e essencial para o cliente. A escuta de reclamações de forma informal, através de conversas com visitantes e Vicentinos, parece contribuir para um clima de rivalidade - funcionários X Vicentinos. O que acaba prejudicando os objetivos dos integrantes da diretoria.

Outro aspecto relevante refere-se à concepção restrita de marketing dos responsáveis pela organização. Percebem o marketing como propaganda, divulgação (comunicação) e não na sua essência que é o de toda organização voltada para criar valor ao cliente, com cada membro buscando satisfazer e servir o cliente. Apesar da comunicação ser um elemento importante, percebemos que ocorre, conforme afirma Kotler (1998), uma inversão, na medida em que, busca-se a divulgação e a propaganda, antes de terem realmente um foco no cliente.

É importante ressaltar que o fenômeno da concorrência se faz presente também para as organizações sem fins lucrativos. Ela surge, por exemplo, na "briga" por doadores/doações, já que existem diferentes instituições na região (APAE, creches, associações de deficientes físicos, dentre outras). Na realidade soa ruim a utilização do termo utilizado por Porter (1989) "vanta- 
gem competitiva" sobre a concorrência, mas de alguma forma esta "concorrência" acaba existindo. As considerações do marketing de valor relatadas neste artigo contribuem para o alcance dessa vantagem. Entretanto, a vantagem competitiva de uma organização deste setor pode contribuir também com outras organizações próximas, em função de seus valores humanitários e/ou religiosos, das parcerias implementadas e dos objetivos sociais destas e de seus integrantes.

\section{CONCLUSÃO}

Esta pesquisa restringiu-se em tentar compreender a visão de marketing de serviços dos responsáveis por uma organização sem fins lucrativos. O objetivo centrou-se em identificar se tais pessoas conhecem quem são, o que desejam e esperam seus clientes, como vêm utilizando os conceitos de marketing e como avaliam a qualidade dos serviços executados na organização à luz da teoria de marketing.

Conclui-se através deste estudo que existe uma utilização de alguns elementos do marketing na organização estudada, mas, conforme apontamos anteriormente, de forma invertida e intuitiva. Na percepção da autora existe uma grande vontade por parte dos integrantes em melhorar as condições em que vivem os internos da organização. Tal vontade é uma condição essencial. Entretanto, é também primordial e necessário para alcançar tal objetivo, a profissionalização dos membros da instituição buscando melhorar a qualidade do atendimento aos diferentes públicos que a organização necessita satisfazer, bem como, a utilização de instru- mentos e critérios formais para avaliação do desempenho, da satisfação dos clientes, dentre outros.

Para melhor aplicação do marketing tornar-se-ia necessário que a organização divulgasse e definisse de forma clara: qual a sua missão? Quais serviços ela está apta a realizar com maior competência? São algumas perguntas importantes para que ela possa "focar" seu trabalho e melhorar a qualidade de seus serviços.

Outros aspectos importantes podem ser estudados e aprofundados, mas fogem ao objetivo principal deste estudo.

\section{BIBLIOGRAFIA}

ABRIGO Frei Anselmo da S.S.V. P. de Unaí. Orientação aos visitantes. s.d. $4 \mathrm{p}$.

CHURCHILL, G. A.; PETER, P. Marketing: criando valor para o cliente. São Paulo: Saraiva, 2000.

DRUCKER, P. F. Administração de organizações sem fins lucrativos: princípios e práticas. São Paulo: Pioneira, 1997. FITZSIMMONS, J. A.; FITZSIMMONS, M. J. Administração de serviços: operações, estratégia e tecnologia de informação. Porto Alegre: Bookman, 2000.

KOTLER, P. Administração de marketing: análise, planejamento, implementação e controle. São Paulo: Atlas, 1998.

MCKENNA, R. Marketing de relacionamento. São Paulo: Publifolha, 1999.

NASCIMENTO, A. M. M. Preparando as organizações do terceiro setor para a adoção de um sistema de coleta, tratamento, análise e uso de informações estratégicas. 1999 . 73f. Dissertação (Mestrado em Information Stratégique et Critique) - Université Aix - Marseille III (França), Brasília. 